\section{Somatic Embryogenesis in Habanero Pepper (C. chinense Jacq.) From Cell Suspensions}

\author{
Patricia Yolanda Zapata-Castillo, Adriana-Canto Flick, \\ Guadalupe López-Puc, Anabel Solís-Ruiz, Felipe Barahona-Pérez, \\ and Nancy Santana-Buzzy ${ }^{1}$ \\ Unidad de Bioquímica y Biología Molecular de Plantas, Centro de \\ Investigación Científica de Yucatán, Calle 43 \#130, Chuburná de Hidalgo, \\ Mérida, Yucatán, 97200, México
}

\section{Lourdes Iglesias-Andreu}

Laboratorio de Biotecnología y Ecología Aplicada, Universidad Veracruzana, Campus para la Cultura, las Artes y el Deporte, Av. de las Culturas Veracruzanas No. 101, Colonia Emiliano Zapata, CP 91090, Jalapa, Veracruz, México

Additional index words. Somatic embryogenesis, thidiazuron, cells in suspension, Capsicum

Abstract. To induce the somatic embryogenesis of Habanero pepper, different culture media and different types of explants (node, internode, hypocotyl, half seeds, and fruit segments) were evaluated. For the induction of embryogenic callus, $9.05 \mu \mathrm{M}$ of 2,4-dichlorofenoxiacetic acid, $3 \%$ sucrose, and $0.8 \%$ gelrite were added to the basic MS medium over a period of 30 days at $25 \pm 2{ }^{\circ} \mathrm{C}$ under continuous light $\left(40-50 \mu \mathrm{mol} \cdot \mathrm{m}^{2} \cdot \mathrm{s}^{-1}\right)$. Once the callus formed, they were transferred to liquid medium using the same induction formulation. Somatic embryogenesis only occurred from explants of hypocotyl and in the presence of $3.4 \mu \mathrm{M}$ thidiazuron. This constitutes the first proposal of a protocol for the "induction of somatic embryogenesis in Habanero pepper (Capsicum chinense Jacq.) from cell suspensions."

Although Capsicum is considered to be a genus recalcitrant to in vitro morphogenesis, the regeneration of chili plants has been reported by several authors (Agrawal and Chandra, 1983; Arroyo and Revilla, 1991; Binzel et al., 1996a, 1996b; Buyukalaca and Mavituna, 1996; Ezura et al., 1993; Fari and Czako, 1981; Ge et al., 1998; Gunay and Rao, 1978; Phillips and Hubstenberger, 1985; Valera-Montero and Ochoa-Alejo, 1992), and although less frequently, somatic embryogenesis has also been obtained (Binzel et al., 1996a, 1996b; Buyukalaca and Mavituna, 1996; Harini and Sita, 1993; Jo et al., 1996; Kintzios et al., 2001; Steinitz et al., 2003). However, all these reports, most of which are restricted to cultivars of the species Capsicum annuum, clearly show that efficiency in plant regeneration and the reproducibility of the protocols are as yet very poor. To facilitate development of plant biotechnology-based cultivar improvement

Received for publication 17 May 2006. Accepted for publication 3 Aug. 2006.

We thank the Secretaría de Agricultura, Ganadería, Desarrollo Rural, Pesca y Alimentación (SAGARPA), the Sistema Nacional de Recursos Fitogenéticos para la Alimentación y la Agricultura (SINAREFI) and the Fundación Produce Yucatán for the economic support we have received for the realization of this work.

${ }^{1}$ To whom reprint requests should be addressed; e-mail buzzy@cicy.mx. for this species, considerable effort has been devoted to developing and optimizing efficient in vitro regeneration protocols. Somatic embryogenesis, the production of bipolar structures from somatic cells, is of considerable theoretical and practical importance because it can be used to combine efficient cloning with genetic modification (Sharp et al., 1980).

In the case of Capsicum chinense, it is essential to establish a reliable and reproducible regeneration system that will allow the incorporation of desirable genes through esis is the only efficient way to regenerate complete plants from individual cells, and with this system, the risk of undesirable chimerical plants is minimal. cum annuum L.) was initially developed through the culture of anthers (Vagera, 1990). Other authors have also explored the somatic embryogenesis of chili from immagenetic transformation. Somatic embryogen-

Somatic embryogenesis of chili (Capsi(C. chinense Jacq.) in liquid media. ture zygotic embryos (Binzel et al., 1996a; Harini and Sita, 1993; Jo et al., 1996), from mature zygotic embryos (Buyukalaca and Mavituna, 1996), and from leaves (Kintzios et al., 2001). With the exception of Buyukalaca and Mavituna (1996), who obtained somatic embryos of C. annuum from cell suspensions, in all these reports, the somatic embryos were obtained directly from the explant. Our objective in this study is to develop a protocol to induce the somatic embryogenesis of Habanero pepper ( $C$. chinense Jacq.) from cell suspensions as part of a project that will use biotechnologic techniques for the genetic improvement of this species.

\section{Materials and Methods}

Preparation of explants. Seeds of the cultivar Rux-02 (red type) of Habanero pepper (Capsicum chinense Jacq.) were first submerged in ethanol at $70 \%(\mathrm{v} / \mathrm{v})$ for $5 \mathrm{~min}$ and subsequently in a solution of commercial chlorine (Cloralex, 6\% active chlorine) diluted to $30 \%(\mathrm{v} / \mathrm{v})$ for $15 \mathrm{~min}$ with constant stirring. The seeds were then rinsed three to four times with sterile distilled water, placed on sterile filter paper to eliminate excess moisture from their surface, and deposited in the culture media. For germination, the seeds were placed in MS media, supplemented with $1.156 \mu \mathrm{M}$ giberelic acid $\left(\mathrm{GA}_{3}\right), 3 \%(\mathrm{w} / \mathrm{v})$ of sucrose, and $0.2 \%(\mathrm{w} / \mathrm{v})$ of gelrite.

The behavior of different types of explants (nodes, internodes, hypocotyls, half seeds, and fruit segments) in the induction media (Table 1) was evaluated to select the most adequate explant for the induction of friable callus. The explants were taken from aseptic plants 20 to $25 \mathrm{~d}$ after in vitro germination of the seeds. Twenty explants were used in each treatment distributed in five containers. Each treatment was repeated three times.

Induction of somatic embryogenesis. In all the treatments, the basic medium recommended by Murashige and Skoog (1962) was used supplemented with sucrose (3\%), thiamine-HCl $(29.6 \mu \mathrm{M})$, myo-inositol (554.93 $\mu \mathrm{M})$, and cisteine- $\mathrm{HCl}(142.3 \mu \mathrm{M})$. For the induction of callus, $9.05 \mu \mathrm{M}(2,4-\mathrm{D}), 3 \%$ sucrose, and $0.8 \%$ gelrite were added to the basic medium, and incubation was carried out over a period of $30 \mathrm{~d}$ at $25 \pm 2{ }^{\circ} \mathrm{C}$ under continuous light $\left(40-50 \mu \mathrm{mol} \cdot \mathrm{m}^{2} \cdot \mathrm{s}^{-1}\right)$. Once the callus formed, it was transferred to a liquid medium maintaining the same composition as the initial medium but without gelrite and with half the concentration of 2,4-D. The suspensions were established by

Table 1. Treatments evaluated during the induction of somatic embryogenesis in Habanero pepper

\begin{tabular}{lllccc}
\hline \multicolumn{5}{c}{ Treatments } \\
\hline T1 & \multicolumn{1}{c}{ T2 } & \multicolumn{1}{c}{ T3 } & T4 & T5 & T6 \\
\hline MS-KNO & MS & MS & MS-KNO & MS & MS-KNO $_{3}$ \\
K-citrate & K-citrate & K-citrate & - & K-citrate & K-citrate \\
$\quad(18 \mathrm{mM})$ & $(18 \mathrm{mM})$ & $(18 \mathrm{mM})$ & & $(18 \mathrm{~mm})$ & $(18 \mathrm{mM})$ \\
$2,4-\mathrm{D}$ & - & $2,4-\mathrm{D}$ & $2,4-\mathrm{D}$ & ZEA & TDZ \\
$(9.05 \mu \mathrm{M})$ & & $(9.05 \mu \mathrm{M})$ & $(9.05 \mu \mathrm{M})$ & $(10 \mu \mathrm{M})$ & $(3.4 \mu \mathrm{M})$ \\
\hline
\end{tabular}


inoculating $1 \mathrm{~g}$ of callus with 1 month of induction into $250 \mathrm{ml}$ erlenmeyer flasks containing $50 \mathrm{ml}$ of liquid medium. The cultures were maintained in agitation at $100 \mathrm{rpm}$ under the same light and temperature conditions used in the callus induction stage. Subcultures were carried out every $14 \mathrm{~d}$ over a period of 2 months. After this period, the biomass was transferred to MS medium without potassium nitrate $\left(\mathrm{KNO}_{3}\right)$, supplemented with $18 \mathrm{~mm}$ potassium citrate (K-citrate), and the 2,4-D was reestablished at the original concentration of $9.05 \mu \mathrm{M}$. The cells were maintained in this medium for 3 weeks. Subsequently, the ammonium nitrate $\left(\mathrm{NH}_{4} \mathrm{NO}_{3}\right)$ was reduced to $10 \mathrm{~mm}, 8.688 \mathrm{~mm}$ of L-proline was added, the 2,4-D and potassium citrate were omitted, and the cellular suspension was maintained in constant agitation $(70 \mathrm{rpm})$ under continuous light $\left(40-50 \mu \mathrm{mol} \cdot \mathrm{m}^{2} \cdot \mathrm{s}^{-1}\right)$ for 2 months. After this culture period, the cells were submitted to different treatments for the induction of somatic embryogenesis (Table 1).

In all cases, the $\mathrm{pH}$ was adjusted to 5.8 , and sterilization was carried out in autoclave at $1.2 \mathrm{~atm}$ of pressure, for $15 \mathrm{~min}$ at $121{ }^{\circ} \mathrm{C}$. Each treatment was repeated three times.

Statistical analysis. Data were analyzed using SigmaStat V. (Jandel Corporation, San Rafeal, Calif.).

\section{Results}

Response of different types of explants to callus induction. As can be seen in Figure 1, with the exception of fruit segments that did not respond, and of internodes with a $30 \%$ response, the remaining explants showed a considerable capacity for the formation of callus $(80 \%$ to $100 \%)$, particularly the hypocotyl. However, as a result of the characteristics and quality of the callus formed, seed halves proved to be the least appropriate explant for the induction of callus, because they presented a compact consistency, slow growth, and, after the second subculture, a sudden necrosis was observed. The other explants evaluated (hypocotyls, nodes, and internodes) presented better characteristics in the callus. Moreover, in the case of the hypocotyl, it was possible to achieve a friable granulose callus with a high embryogenic capacity, which also conserved these characteristics after eight to 10 subcultures carried out every $21 \mathrm{~d}$.

The characteristics of the callus formed from the hypocotyl showed considerable differences in comparison with those of the callus



Fig. 1. Response (\%) of the different types of explants of Habanero pepper during callus induction. Vertical bars represent \pm standard deviation $(\mathrm{n}=3)$. formed from the remainder of the explants evaluated. They were friable granulose callus; initially white, they became creamy white after the second subculture (42 d), and throughout their permanence in solid media, they conserved their consistency and texture indefinitely (Fig. 2A, B). The calluses obtained from the hypocotyl showed a rapid disaggregation once they were transferred to the liquid media, producing a very homogenous cellular suspension, creamy-white in color, $14 \mathrm{~d}$ after inoculation (Fig. 2C, D). As a result of the rapid growth and the density of the cellular suspension, subcultures were carried out every $14 \mathrm{~d}$.
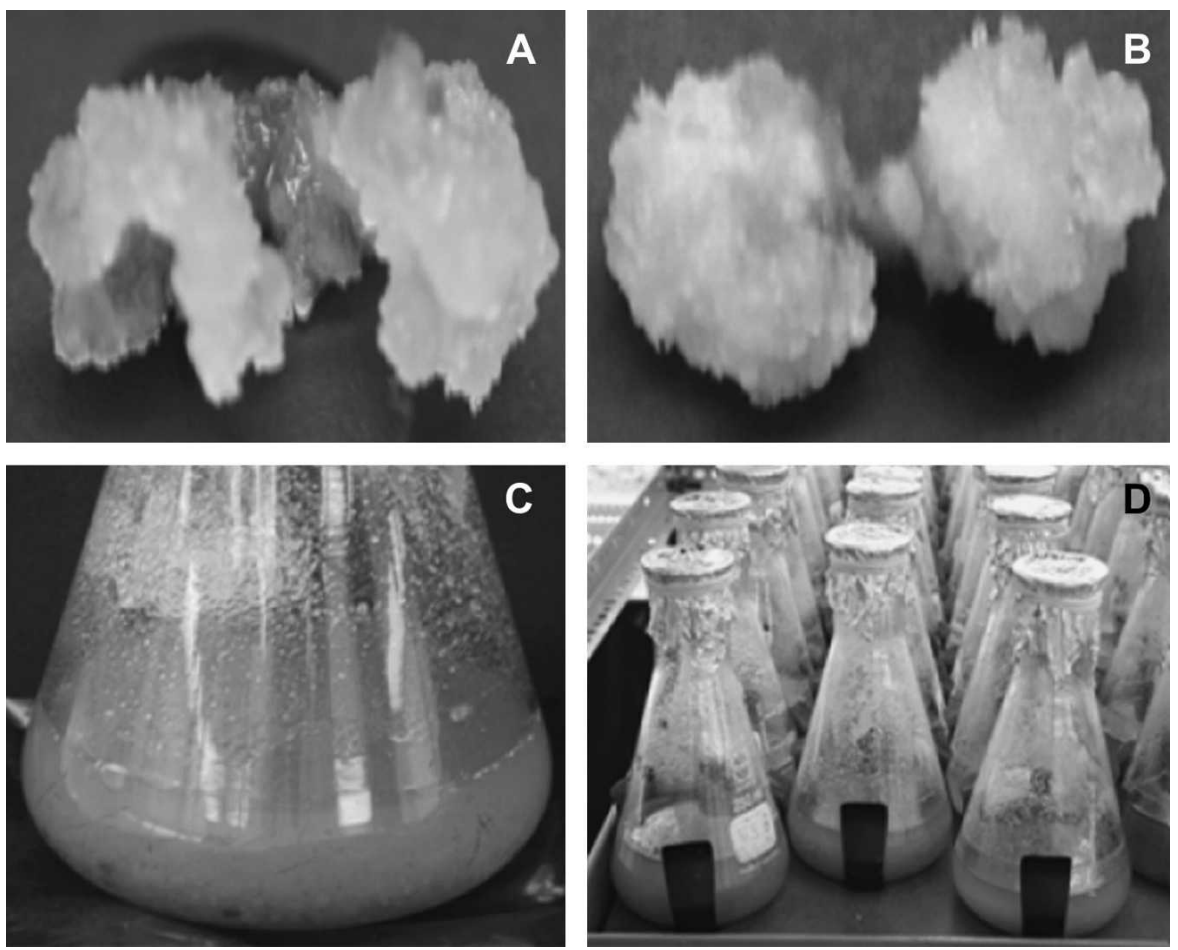

Fig. 2. Friable callus obtained from the hypocotyls. It was initially (A) white and subsequently (B) creamy white. Note the capacity of disaggregation in liquid media $(\mathbf{C}, \mathbf{D})$.
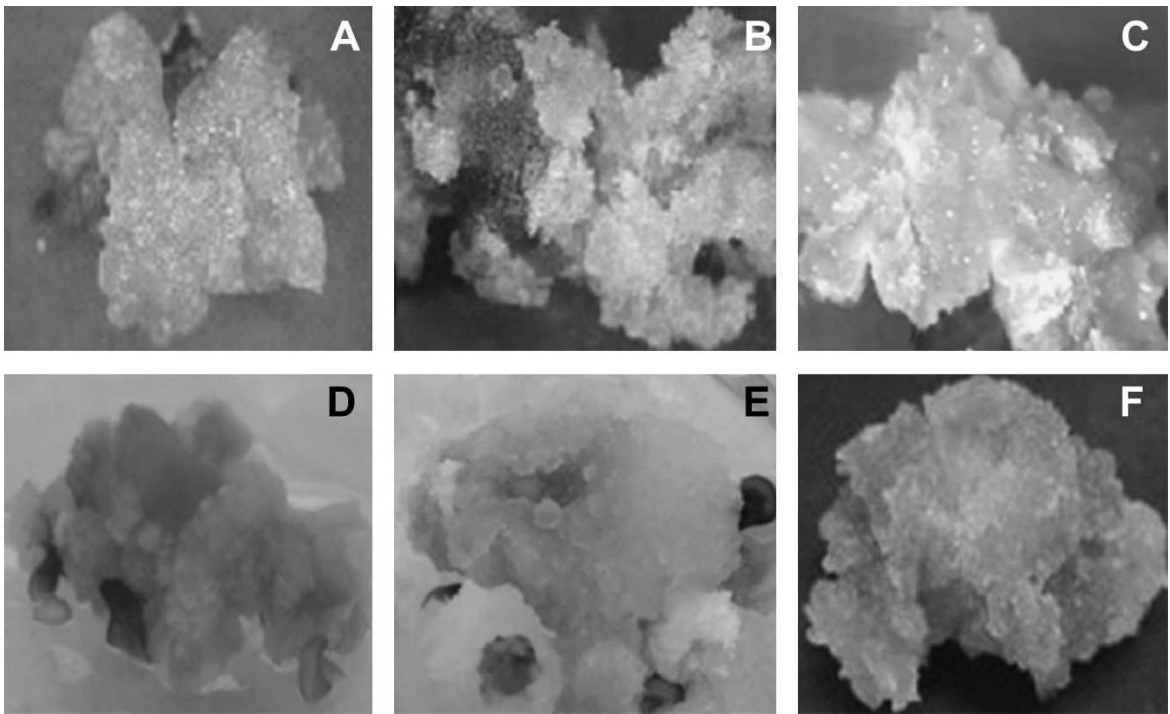

Fig. 3. Diversity of tones, consistency, and texture of the calluses obtained in the culture media evaluated: (A-C) compact callus and spongy callus obtained from (D) half seed, (E) node, and (F) internode. 
hypocotyl when it was inoculated in different media for embryo induction (Table 1). The results were notably different in each case. When cell mass of Habanero pepper was inoculated in T1 medium, a very fine cellular suspension was generated with small, quickgrowing, creamy white cellular aggregates, which were not capable of generating embryogenic structures (Fig. 4A); on the other hand, when the biomass was inoculated
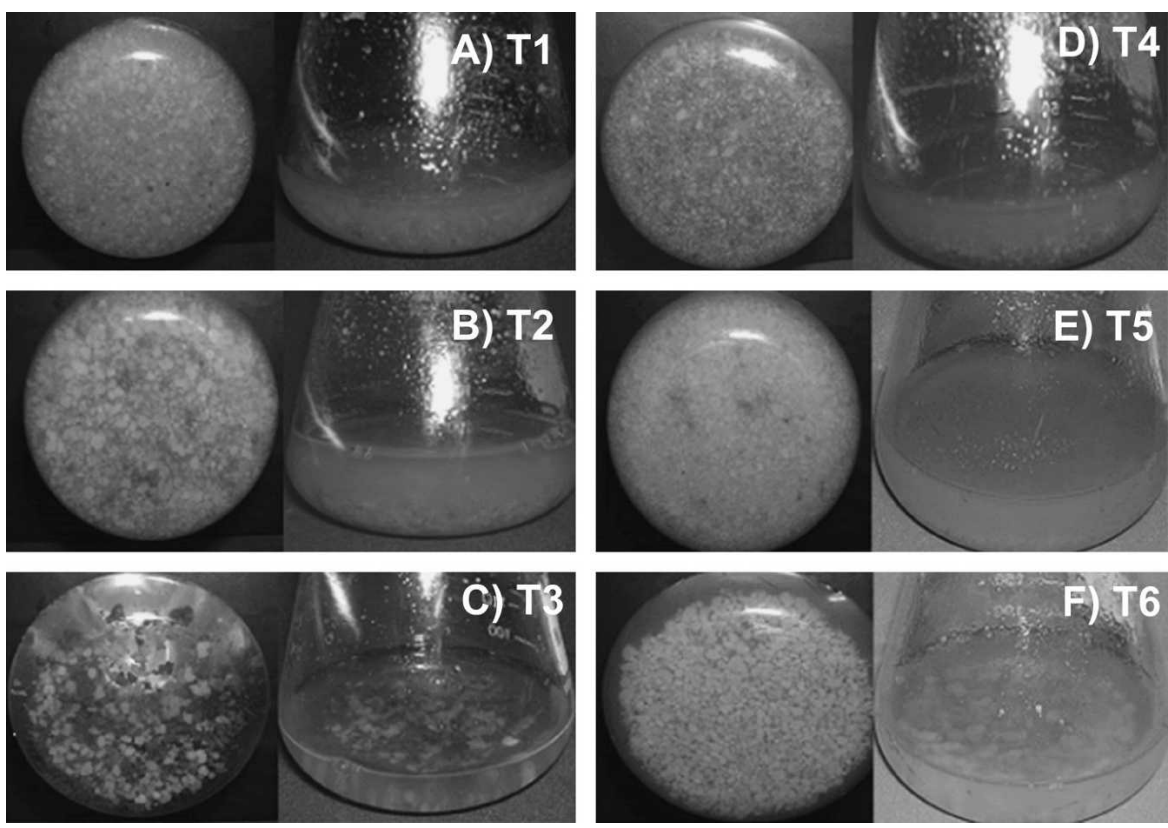

Fig. 4. Diversity in the shape and size of the cellular structures formed in the treatments T1-T6.
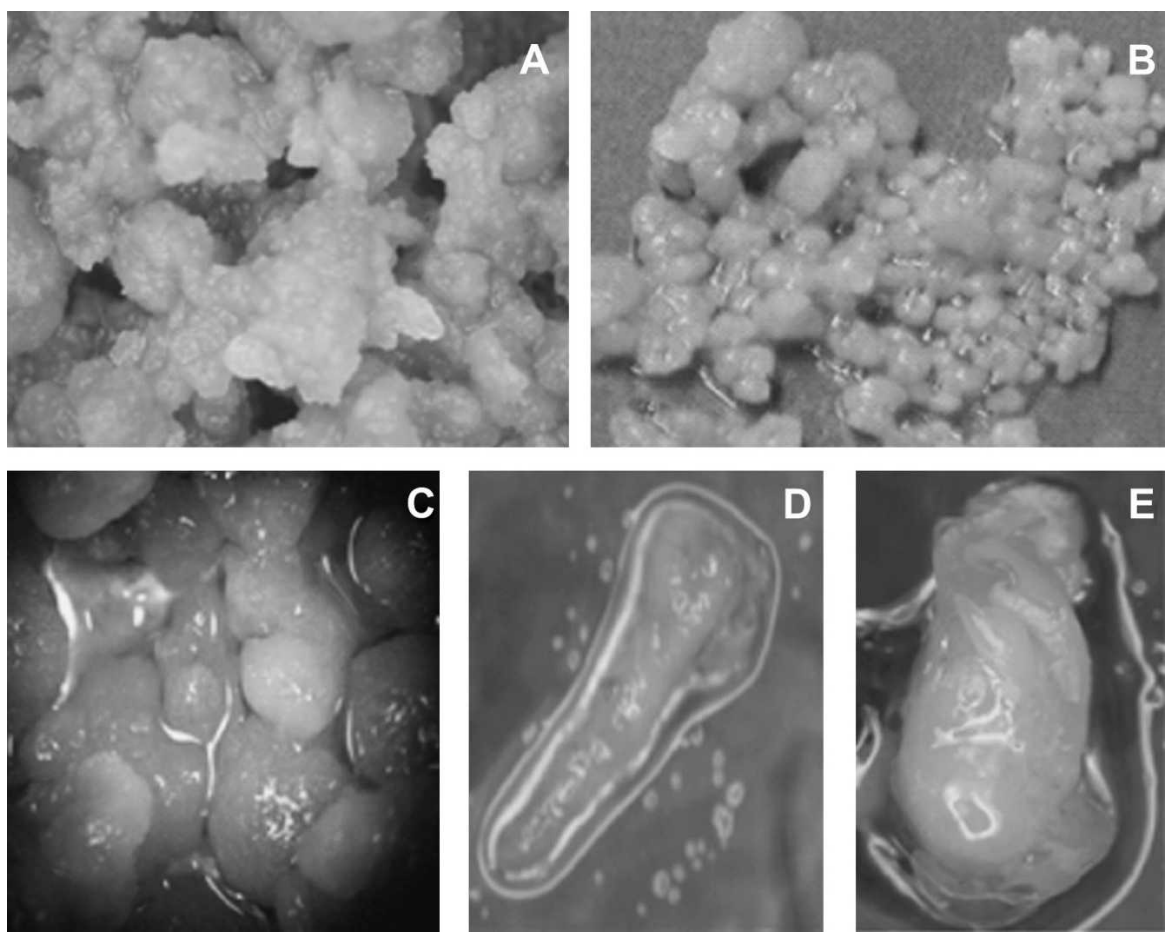

Fig. 5. Somatic embryogenesis of the Habanero pepper (Capsicum chinense Jacq.) in the media T6. (A) Highly embryogenic biomass; (B) high frequency and uniformity of somatic embryos in the globular stage; (C) somatic embryos in different stages of development (heart-shaped and torpedo); (D) embryo in the cotyledonary stage; (E) germinated somatic embryo.
Only in the T6 medium was it possible to observe a highly embryogenic biomass (Fig. 4F) composed of clusters of somatic embryos in early stages of their development (Fig. 5A). This embryogenic biomass formed somatic embryos not only in a very high frequency, but also with a high synchronism of the process, particularly in the formation of somatic embryos in the globular, heartshaped and torpedo stages (Fig. 5B, C). Moreover, although the somatic embryos reach the cotyledonary stage and their germination still remains low ( $20 \%$ to $30 \%)$, the embryos that did achieve this stage showed a normal morphology (Fig. 5D, E).

\section{Discussion}

One of the most relevant results observed during the establishment of a protocol of somatic embryogenesis for the Habanero pepper was undoubtedly the fact that the hypocotyl proved to be the explant whose cells showed greater predisposition for the formation of somatic embryos. The use of hypocotyl is less laborious; there is a greater availability of plant material and a faster response to in vitro culture. Most of the protocols established to date, in all probability as a result of the recalcitrance of the species, have been limited to the use of the zygotic embryo, mature or immature, for inducing the formation of somatic embryos (Binzel et al., 1996a; Buyukalaca and Mavituna, 1996; Harini and Sita, 1993; Jo et al., 1996; Steinitz et al., 2003). Only Kintzios et al. (2001) reported the formation of somatic embryos from mature leaves of $C$. annuum, and, with the exception of Buyukalaca and Mavituna (1996) who obtained somatic embryos from cells in suspension, in all the reports of indirect somatic embryogenesis carried out in the Capsicum species, the somatic embryos were obtained directly from the callus in solid media (Jo et al., 1996; Kintzios et al., 2001). On the other hand, most reports agree that somatic embryogenesis was controlled by the $2,4-\mathrm{D}$ alone or combined with thidiazuron (TDZ) (Binzel et al., 1996b), coconut water (Binzel et al., 1996b; Harini and Sita, 1993) or BAP (Kintzios et al., 2001). In contrast, Binzel et al. (1996a) reported the formation of somatic embryos directly from the explant, when zygotic embryos of chili (Capsicum annuum) were used, only in the presence of 2,4-D. Although Steinitz et al. (2003) were able to induce somatic embryos in 12 genotypes of Capsicum annuum using either 2,4-D or centrophenoxine, the greatest number of embryos per explant was obtained with the latter.

In the case of Habanero pepper, we found that the 2,4-D was required at a higher concentration $(9.05 \mu \mathrm{M})$ at the time of induction of the embryogenic callus; however, once the callus was transferred to the liquid media for disaggregation and cell multiplication, it was necessary to reduce the 2,4-D to half the initial concentration $(4.5 \mu \mathrm{M})$, and somatic embryos formed only when it was 
totally suppressed from the culture media and TDZ was added. Similar results were reported by Buyukalaca and Mavituna (1996) and Jo et al. (1996), although when they suppressed the 2,4-D, they used only ABA at the time of somatic embryo maturing. However, in marked contrast with all the reports referring to the Capsicum species, in the protocol we are reporting, the formation of globular embryos was exceptionally well expressed if we take into account that practically all the biomass obtained became somatic embryos. It is likely that one of the main factors that could have had an influence on the explosive conversion to somatic embryos of the Habanero pepper cells is precisely the suppression of the 2,4-D and the addition of TDZ at the time of inducing the formation of the embryos. Thidiazuron, a substituted phenyl urea (N-phenyl-1,2,3thidiazol-5-yl urea), is a potent plant growth regulator, which exhibits cytokinin-like activity in various culture systems (Khan et al., 2006). Although 2,4-D is considered an auxin promoter of somatic embryogenesis in plants, the formation of somatic embryos usually occurs when it is suppressed from the culture media. There are also a number of reports stating that, with some species, TDZ has proved to be much more potent than Zeatine for stimulating in vitro morphogenesis, and in some cases, it can be more active than the cytokinins (Mok et al., 1987; Santana-Buzzy et al., 2005, 2006). There have been reports that, in some species, the TDZ can stimulate both processes, somatic embryogenesis and the proliferation of adventitious shoots (Bates et al., 1992; Fiola et al., 1990; Santana-Buzzy et al., 2005), and although there are few reports available, TDZ has been used in the range of 0.5 to $10 \mu \mathrm{M}$ to stimulate somatic embryogenesis from cotyledons of white ash (Bates et al., 1992; Preece and Bates, 1990;), eastern black walnut (Neuman et al.,1988, 1993), Rubus (Fiola et al.,1990), and Vitis vinifera L. (Matsuta and Hirabayashi, 1989). TDZ was successfully applied to induce organogenesis and somatic embryogenesis from different explants such as half seedlings, intact seedlings, immature embryos, embryonic hypocotyls, embryonic cotyledons, cotyledons, leaves, cotyledonary nodes, and shoot tips of pepper (Binzel et al., 1996a, 1996b; Dabauza and Pena, 2001; Hyde and Phillips, 1996; Kaparakis and Alderson, 2002; Manoharan et al., 1998; Ramírez-Malagon and Ochoa-Alejo, 1996; Szasz et al., 1995; Venkataiah et al., 2003). Thidiazuron shows high efficiency in stimulating cytokinindependent shoot regeneration in a wide variety of plants (Huetteman and Preece, 1993; Murthy et al., 1998) and, in particular, for the micropropagation of many recalcitrant species (Huetteman and Preece, 1993). Perhaps TDZ is more active in stimulating adventitious shoot formation than somatic embryogenesis. However, it is premature to say that TDZ is more active in shoot organogenesis than somatic embryogenesis until more detailed studies are published.

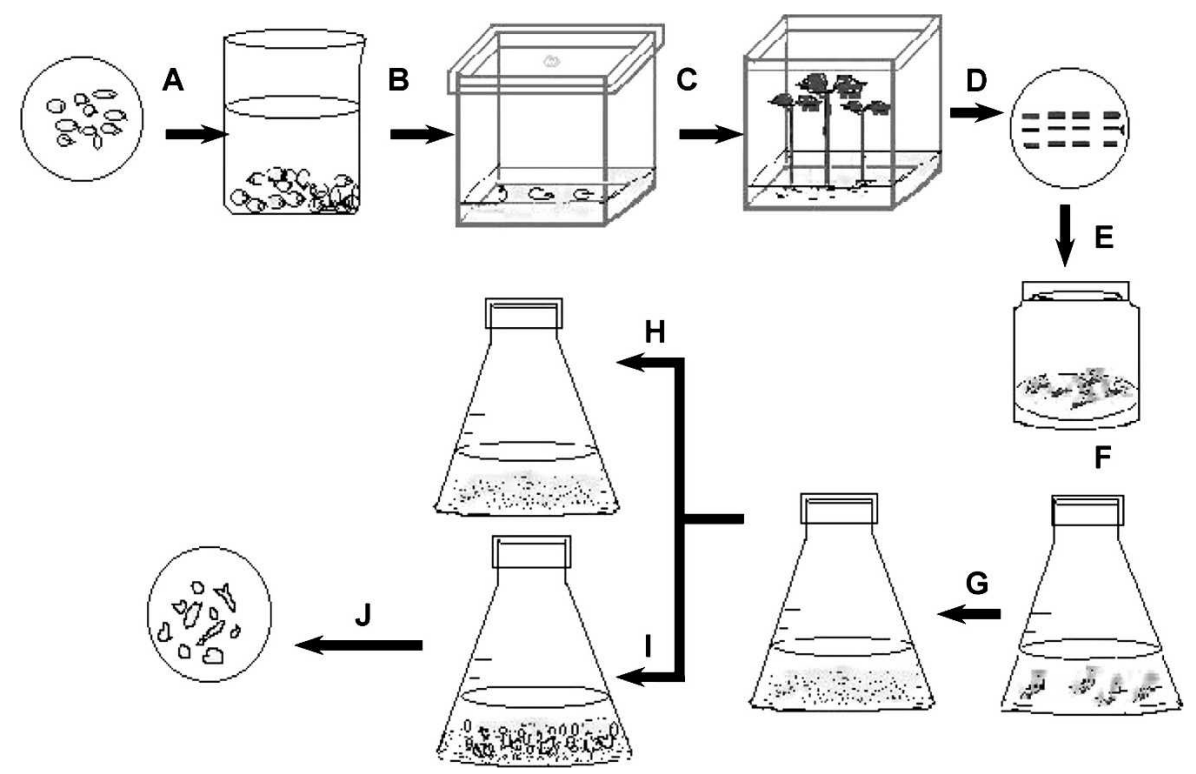

Fig. 6. Established protocol for the induction of somatic embryogenesis in Habanero pepper (capsicum chinense Jacq.): a disinfection of Habanero pepper seeds. (A) In vitro germination of seeds. (B) Source of aseptic explants (15-20-d-old plantlets). (C) Dissection of aseptic plants and selection of initial explant: hypocotyl (21 d of germination). (D) Induction of embryogenic callus in a media containing MS, 2,4-D $(9.05 \mu \mathrm{M})$, sucrose $(3 \%)$, thiamine- $\mathrm{HCl}(29.6 \mu \mathrm{M})$, cisteine-HCl $(42.3 \mu \mathrm{M})$, myo-inositol $(555 \mu \mathrm{M})$, and gelrite $(0.2 \%) ;(20 \mathrm{ml} / \mathrm{jar} ; 30 \mathrm{~d}$ of culture). Incubated under continuous light 40 $50 \mu \mathrm{mol} \cdot \mathrm{m}^{2} \cdot \mathrm{s}^{-1}$ at $25 \pm 2{ }^{\circ} \mathrm{C}$. (E) Cellular disaggregation in liquid medium composed of MS, 2,4-D $(4.5 \mu \mathrm{M})$, sucrose $(3 \%)$, thiamine- $\mathrm{HCl}(29.6 \mu \mathrm{M})$, cisteine- $\mathrm{HCl}(42.3 \mu \mathrm{M})$, and myo-inositol $(555 \mu \mathrm{M})$; $70 \mathrm{~d}$ of culture with subcultures every $14 \mathrm{~d}(10-\mathrm{ml}$ cell suspension in $100 \mathrm{ml}$ of fresh medium), incubation at $100 \mathrm{rpm}$, under continuous light $40-50 \mu \mathrm{mol} \cdot \mathrm{m}^{2} \cdot \mathrm{s}^{-1}$ at $25 \pm 2{ }^{\circ} \mathrm{C}$. (F) Establishment of a cell line in a medium containing MS, 2,4-D (4.5 $\mu \mathrm{M})$, sucrose $(3 \%)$, thiamine- $\mathrm{HCl}(29.6 \mu \mathrm{M})$, cisteine$\mathrm{HCl}(42.3 \mu \mathrm{M})$, and myo-inositol $(555 \mu \mathrm{M}) ; 70 \mathrm{~d}$ of culture, with subcultures every $14 \mathrm{~d}$, at $100 \mathrm{rpm}$, under continuous light $40-50 \mu \mathrm{mol} \cdot \mathrm{m}^{2} \cdot \mathrm{s}^{-1}$ at $25 \pm 2{ }^{\circ} \mathrm{C}$. (G) Maintenance of the cell line (with the same culture conditions as in the previous step). (H) Induction of somatic embryos in a medium containing MS without $\mathrm{KNO}_{3}$, sucrose (3\%), thiamine- $\mathrm{HCl}(29.6 \mu \mathrm{M})$, cisteine- $\mathrm{HCl}(42.3 \mu \mathrm{M})$, myo-inositol (555 $\mu \mathrm{M}), \mathrm{K}$-citrate $(18 \mathrm{~mm})$, and $3.4 \mu \mathrm{M}$ of thidiazuron. Culture time: $90 \mathrm{~d}$ with subcultures every $21 \mathrm{~d}$, at $100 \mathrm{rpm}$, under continuous light $40-50 \mu \mathrm{mol} \cdot \mathrm{m}^{2} \cdot \mathrm{s}^{-1}$ at $25 \pm 2{ }^{\circ} \mathrm{C}$. Somatic embryos in different stages.

As a result of this study, a highly efficient system for the induction of somatic embryogenesis in Habanero pepper was established in which, in contrast with the majority of the protocols reported for Capsicum annuum, a hypocotyl was used instead of a zygotic embryo as the initial explant, making the system much less laborious and allowing greater availability of plant tissue. The suppression of $\mathrm{KNO}_{3}$ and the presence of K-citrate and TDZ facilitated not only the formation of somatic embryos, but also the development and germination of these in only one culture medium with subcultures every $14 \mathrm{~d}$ over a period of 2 months. Probably the roll of K-citrate was a reducer of phenolic compounds, avoiding their interference during embryo histodifferentiation. When K-citrate was present in the culture media, the formed embryos and the suspension were less dark.

In conclusion, we have established the first and most promising system for the obtainment of somatic embryos of the Habanero pepper from cells in suspension using hypocotyls (Fig. 6). Taking into account that this species belongs to a genus recalcitrant to morphogenesis, genetic improvement of pepper cultivars for disease and insect pest resistance, among other characters, can be efficiently achieved through genetic engineering. To date, difficulties in regeneration (shoot elongation from induced adventitious shoot buds) and nonreproducibility of results in tissue cultures of pepper have restricted work on genetic transformation. This protocol would appear to be attractive and quite promising for the development of basic and applied research and could in fact constitute a very useful process to obtain Habanero pepper (Capsicum chinense J.) cultivars more adaptable to the conditions of stress affecting this species.

\section{Literature Cited}

Agrawal, S. and N. Chandra. 1983. Differentiation of multiple shoot buds and plantlets in cultured embryos of Capsicum annuum L. var. Mathania. Curr. Sci. 52:645-646.

Arroyo, R. and M.A. Revilla. 1991. In vitro plant regeneration from cotyledon and hypocotyl segments in two bell pepper cultivars. Plant Cell Rep. 10:414-416.

Bates, S., J.E. Preece, N.E. Navarrete, J.W. Van Sambeek, and G.R. Gaffney. 1992. Thidiazuron stimulates shoot organogenesis and somatic embryogenesis in white ash (Fraxinus americana L.). Plant Cell Tiss. Org. Cult. 31:21-30.

Binzel, M.L., N. Sankhla, S. Joshi, and D. Sankhla. 1996a. Induction of direct somatic embryogenesis 
and plant regeneration in pepper (Capsicum annuum L.). Plant Cell Rep. 15:536-540.

Binzel, M.L., N. Sankhla, S. Joshi, and D. Sankhla. 1996b. In vitro regeneration in chile pepper (Capsicum annuum L.) from 'half-seed explants.' Plant Growth Regulat. 20:287-293.

Buyukalaca, S. and F. Mavituna. 1996. Somatic embryogenesis and plant regeneration of pepper in liquid media. Plant Cell Tiss. Org. Cult. 46:227-235.

Dabauza, M. and L. Pena. 2001. High efficiency organogenesis in sweet pepper (Capsicum annuum L.) tissues from different seedling explants. Plant Growth Regulat. 33:221-224.

Ezura, H., S. Nishimiya, and M. Kasumi. 1993. Efficient regeneration of plants independent of exogenous growth regulators in bell pepper (Capsicum annuum L.). Plant Cell Rep. 12:676-680.

Fari, M. and M. Czako. 1981. Relationships between position and morphogenetic response of pepper hypocotyls explant cultured in vitro. Sci. Hort. 15:207-213.

Fiola, J.A., M.A. Hassan, H.J. Swartz, R.H. Bors, and R. McNicols. 1990. Effect of thidiazuron, light influence rates and kanamycin on in vitro shoot organogenesis from excised Rubus cotyledons and leaves. Plant Cell Tiss. Org. Cult. 20:223-228.

Ge, K.L., T. Sasakuma, and M. Tanaka. 1998. Callus induction and plant regeneration in Capsicum. Acta Bot. Sin. 31:962-965.

Gunay, A.L. and P.S. Rao. 1978. In vitro plant regeneration from hypocotyls and cotyledon explants of red pepper (Capsicum). Plant Sci. Lett. 11:365-372.

Harini, I. and G.L. Sita. 1993. Direct somatic embryogenesis and plant regeneration from immature embryos of chilli (Capsicum annuum L.). Plant Sci. 89:107-112.

Huetteman, C.A. and J.E. Preece. 1993. Thidiazuron: A potent cytokinin for woody plant tissue culture. Plant Cell Tiss. Org Cult. 33:105-119.

Hyde, C. and G.C. Phillips. 1996. Silver nitrate promotes shoot development and plant regeneration of chile pepper (Capsicum annuum L.) via organogenesis. In Vitro Cell. Dev. Biol. Plant 32:72-80.

Jo, J.-Y., E.-Y. Choi, D. Choi, and K.-W. Lee. 1996. Somatic embryogenesis and plant regen- eration from immature zygotic embryo culture in pepper (Capsicum annuum L.). J. Plant. Biol. 39:127-135.

Kaparakis, G. and P.G. Alderson. 2002. Influence of high concentrations of cytokinins on the production of somatic embryos by germinating seeds of tomato, aubergine and pepper. J. Hortic. Sci. Biotechnol. 77:186-190.

Khan, H., I. Siddique, and M. Anis. 2006. Thidiazuron induced somatic embryogenesis and plant regeneration in Capsicum annuum. Biol. Plant. 50:789-792.

Kintzios, S., J.B. Drossopolous, and Ch. Lymperopoulos. 2001. Effect of vitamins and inorganic micronutrients on callus growth and somatic embryogenesis from leaves of chillipepper. Plant Cell Tiss. Org. Cult. 67:55-62.

Manoharan, M., C.S.S. Vidya, and G.L. Sita. 1998. Agrobacterium mediated genetic transformation in hot chilli (Capsicum annuum L.var. Pusa Jwala). Plant Sience 131:77-83.

Matsuta, N. and T. Hirabayashi. 1989. Embryogenic cell lines from somatic embryos of grape (Vitis vinifera L.). Plant Cell Rep. 7:684-687.

Mok, M.C., D.W.S. Mok, J.E. Turner, and C.V Mujer. 1987. Biological and biochemical effects of cytokinin-active phenyl urea derivates in tissue culture systems. HortScience 22:1194-1196.

Murashige, T. and F. Skoog. 1962. A revised medium for rapid growth and bioassay with tobacco tissue culture. Physiol. Plant. 15:473497.

Murthy, B.N.S., S.T. Murch, and P.K. Saxena. 1998. Thidiazuron: A potent regulator of in vitro plant morphogenesis. In Vitro Cell. Dev. Biol. Plant 34:267-275.

Neuman, M.C., J.E. Preece, G.R. Gaffnney, and J.W. Van Sambeek. 1988. Production of somatic embryoid-like structures from immature cotyledonary tissue of black walnut (Juglans nigra L.). HortScience 23:807-810.

Neuman, M.C., J.E. Preece, J.W. Van Sambeek, and G.R. Gaffnney. 1993. Somatic embryogenesis and callus production from cotyledon explants of eastern black walnut (Juglans nigra L.). Plant Cell Tiss. Org. Cult. 32:9-18.

Phillips, G.C. and J.F. Hubstenberger. 1985. Organogenesis in pepper tissue cultures. Plant Cell Tiss. Org. Cult. 4:261-269.
Preece, J.E. and S. Bates. Source tree affects adventitious regeneration of white ash. Abstracts of the 23rd Intl Hort Congr, Firenze, Italy. 1990.

Ramírez-Malagon, R. and N. Ochoa-Alejo. 1996. An improved and reliable chili pepper (Capsicum annuum L.) plant regeneration method. Plant Cell Rep. 16:226-231.

Santana-Buzzy, N., A. Canto-Flick, F. BarahonaPérez, M.C. Montalvo-Peniche, P.Y. ZapataCastillo, A. Solís-Ruíz, A. Zaldívar-Collí, O. Gutiérrez-Alonso, and M.L. Miranda-Ham. 2005. Regeneration of Habanero pepper (Capsicum chinense Jacq.) via organogenesis. HortScience 40:1829-1831.

Santana-Buzzy, N., A. Canto-Flick, L. IglesiasAdreu, M.C. Montalvo-Peniche, G. López-Puc, and F. Barahona-Pérez. 2006. Improvement of in vitro culturing of Habanero pepper by inhibition of ethylene effects. HortScience 41:405-409.

Sharp, W.R., M.R. Sondahl, L.S. Caldas, and L.S. Maraffa. 1980. The physiology of in vitro asexual embryogenesis. Hort. Rev. (Amer. Soc. Hort. Sci.) 2:268-310.

Steinitz, B., M. Küsek, Y. Tabib, I. Paran, and A. Zelcer. 2003. Pepper (Capsicum annuum L.) regenerants obtained by direct somatic embryogenesis fail to develop a shoot. In Vitro Cell. Dev. Biol. Plant 39:296-303.

Szasz, A., G. Nervo, and M. Fari. 1995. Screening for in vitro shoot-forming capacity of seedling explants in bell pepper (Capsicum annuum L.) genotypes and efficient plant regeneration using thidiazuron. Plant Cell Rep. 14:666669.

Vagera, J. 1990. Pepper (Capsicum spp.): In vitro induction of haploids, p. 374-392. In: Y.P.S. Bajaj (ed.). Biotechnology in agriculture and forestry. Vol. 12. Springer, Berlin.

Valera-Montero, L.L. and N. Ochoa-Alejo. 1992. A novel approach for chilli pepper (Capsicum annuum L.) plant regeneration: Shoot induction in rooted hypocotyls. Plant Sci. 84: 215-219.

Venkataiah, P., T. Christopher, and K. Subhash. 2003. Thidiazuron induced high frequency adventitious shoot formation and plant regeneration in Capsicum annuum L. J. Plant Biotechnol. 5:245-250. 